\title{
Análise Comparativa de Téchicas de Estimativa de Fração de COBERTURA VEGETAL POR Urochloa ruziziensis E Urochloa spp. ${ }^{1}$
}

\author{
Comparative Analysis of Measuring Techniques for Canopy Cover Fraction by \\ Urochloa ruziziensis and Urochloa spp.
}

\author{
LIMA, S.F. ${ }^{2}$, TIMOSSI, P.C. ${ }^{2}$ e ASSUNÇÃO, H.F. ${ }^{2}$
}

\begin{abstract}
RESUMO - O potencial de cobertura vegetal do solo por plantas cultivadas é um parâmetro importante para a seleção de espécies forrageiras adaptadas a uma determinada região. Contudo, uma das restrições de uso dessa variável está associada à adoção da técnica de estimativa, uma vez que existem diferentes formas de cálculo. Diante disso, objetivou-se comparar as frações de cobertura do solo cultivado com Urochloa ruziziensis e Urochloa spp., utilizando-se três técnicas de medida: avaliação visual, avaliação por intercepto ou transecto e avaliação por imagens fotográficas. Para isso, foram conduzidos seis ensaios em campo, em delineamento de blocos casualizados. Os ensaios 1, 2 e 3 foram formados pela espécie Urochloa ruziziensis e compostos por três tratamentos, representados pelas três técnicas de medida (visual, por intercepto ou transecto e por imagens fotográficas), com oito repetições. Os ensaios 4, 5 e 6 tiveram arranjo fatorial $2 \times 3$, sendo o fator A formado por duas espécies de capim-braquiária (Urochloa ruziziensis e Urochloa spp. cv. Mulato II) e o fator B pelas três técnicas de medida (visual, por transecto e por imagens fotográficas), com quatro repetições. As medidas das frações de cobertura do solo foram tomadas aos 30, 60 e 90 dias após a semeadura. Constatou-se que, quanto maior a uniformidade da cobertura do solo pelas plantas forrageiras, mais próximos são os valores das frações de cobertura vegetal obtidas pelas três técnicas de estimativa. As técnicas de estimativa visual e por transecto da fração de cobertura do solo foram consideradas semelhantes, já a eficiência da medida pela técnica com imagens fotográficas depende da calibração individual de cada imagem.
\end{abstract}

Palavras-chave: Brachiaria spp., capim-braquiária, forrageira, avaliação visual, avaliação por transecto, avaliação por imagem.

ABSTRACT - The potential of vegetation cover of soil by cover crops is an important parameter for the selection of forage species adapted to a given region. However, one of the restrictions the use this variable is associated the adoption of the estimation technique, since there are different forms of calculation. Thus, the objective was to compare the cover fractional of soil cultivated with Urochloa ruziziensis and Urochloa spp., using three measurement techniques: visual evaluation, evaluation by intercept or transect and evaluation by photographic image. For this, six experiments were conducted in the field, in randomized block design. The experiment 1, 2 and 3 was formed by the species of Urochloa ruziziensis and composed of three treatments, represented by the three measuring techniques (visual evaluation, evaluation by transect and evaluation by photographic image), with eight replications. The experiment 4, 5 and 6 had factorial arrangement $2 \times 3$, the factor A was formed of two species of Urochloa (Urochloa ruziziensis and Urochloa spp. cv. Mulato II) and the factor $B$ by the three measuring techniques (visual evaluation, evaluation by transect and evaluation by photographic image), with four replications. The measures of fractional of cover soil were made at 30, 60 and 90 days after sowing. Was found that the greater the uniformity of soil cover by forage plants, closest are the values of fractional of vegetation cover obtained by the three estimation techniques. The measurement techniques of visual and to transect of the fraction of soil cover were considered similar, and the efficiency of the evaluation by photographic image depend on the individual calibration of each image.

Keywords: Brachiaria spp., brachiaria-grass, forage, visual evaluation, evaluation by transect, evaluation by image.

Recebido para publicação em 25.11.2014 e aprovado em 28.11.2014.

Universidade Federal de Goiás - Regional Jataí, Jataí-GO, Brasil, <suzete.lima@yahoo.com.br>. 


\section{INTRODUÇÃO}

Para o estabelecimento do sistema de plantio direto, torna-se imprescindivel a utilização de plantas que proporcionem boa cobertura do solo (Ceretta et al., 2002). A cobertura do solo é constituída pelo dossel da cultura e pelos resíduos vegetais e sofre contínuas modificações à medida que a cultura se desenvolve e os resíduos vegetais se decompõem (Varella et al., 2002). Segundo Sodré Filho et al. (2008), a utilização de plantas de cobertura pode suprimir o banco de sementes de plantas daninhas no solo, tornando-se prática importante a ser adotada no manejo integrado de plantas daninhas.

A semeadura de gramíneas forrageiras após o cultivo da safra, em substituição ao pousio, se torna uma alternativa viável para a cobertura do solo e supressão de plantas daninhas, levando à redução do banco de sementes do solo ao longo dos anos (Nunes et al., 2006; Ikeda et al., 2007; Timossi et al., 2007; Noce et al., 2008). Na região do cerrado, as espécies do gênero Urochloa têm se destacado na formação de cobertura vegetal do solo no plantio direto, pois se mantêm em crescimento durante a estação seca (Machado $\&$ Assis, 2010).

Entre as características desejáveis das plantas de cobertura estão o rápido estabelecimento inicial e a eficiência na cobertura do solo. Dessa forma, a quantificação desse parâmetro torna-se de grande importância para as pesquisas que estudam o potencial de supressão de plantas daninhas por plantas de cobertura. Alguns autores (Kropff \& Spitters, 1991; Berti \& Satin, 1996) salientam que uma das limitações no uso dessa variável referese à disponibilidade de uma técnica de estimativa confiável, rápida e barata no início de crescimento das plantas.

Existem diferentes técnicas para a determinação da fração de cobertura vegetal do solo (Brower \& Zar 1984; Gazziero et al., 1995; Varella et al., 2002). A técnica adotada deve ser definida de acordo com a finalidade da pesquisa e o grau de exatidão requerido (Cruz et al., 2008). Segundo estes autores, entre as técnicas de medida da fração de cobertura do solo, podem-se citar as estimativas baseadas em inspeções visuais, as quais apresentam a vantagem de serem práticas e de baixo custo.

Outra técnica bastante usada é a utilização de fita métrica ou corda (intercepto ou transecto de linha), com marcas a cada 5 ou $10 \mathrm{~cm}$ para leitura da presença ou ausência de cobertura vegetal sobre o solo (Brower $\&$ Zar, 1984). Também há uma técnica baseada no processamento digital de imagens, captadas por câmeras fotográficas, a qual tem demonstrado ser promissora (Karcher \& Richardson, 2003; Godoy et al., 2007), sendo uma das vantagens deste método o registro permanente da área de pesquisa (Ferreira et al., 2001).

Nesse contexto, objetivou-se comparar as frações de cobertura do solo cultivado com Urochloa ruziziensis e Urochloa spp. cv. Mulato II, utilizando-se três técnicas de medida: avaliação visual, avaliação por intercepto e avaliação por imagens fotográficas.

\section{MATERIAL E MÉTODOS}

Em campo, foram conduzidos seis ensaios para estimativa da fração de cobertura vegetal do solo. Os ensaios foram conduzidos no sudoeste de Goiás, na Universidade Federal de Goiás, Regional Jataí. O solo da área experimental é classificado como Latossolo Vermelho distroférrico (Embrapa, 2006). O clima da região, pela classificação de Köppen, é Aw, mesotérmico, tropical de savana, com chuva no verão e seca no inverno.

O delineamento experimental utilizado nos seis ensaios foi de blocos casualizados. Os ensaios 1,2 e 3 foram compostos por três tratamentos, representados por três técnicas de avaliação: visual, por intercepto ou transecto e por imagens fotográficas, com oito repetições. Nesses ensaios, foi cultivado o capim braquiária-ruziziense. Os ensaios 4, 5 e 6 foram dispostos em arranjo fatorial $2 \times 3$, sendo o fator A formado por duas espécies de capim-braquiária (Urochloa ruziziensis e Urochloa spp. cv. Mulato II) e o fator B pelas três técnicas de avaliação (visual, por transecto e por imagens fotográficas), com quatro repetições. Na semeadura das braquiárias, foram adotados três métodos: a lanço, a lanço com leve incorporação e em linha (Tabela 1). A área de cada unidade experimental foi representada por parcelas com $4 \mathrm{~m}$ 
Tabela 1 - Descrição dos ensaios 1, 2, 3, 4, 5 e 6 com os respectivos métodos de estimativa da cobertura vegetal (visual, transecto e fotográfico), métodos de semeadura (a lanço, a lanço com leve incorporação e em linha) e espécies de braquiária (Urochloa ruziziensis e Urochloa spp. cv. Mulato II)

\begin{tabular}{|l|c|c|c|c|c|c|}
\hline \multirow{2}{*}{$\begin{array}{c}\text { Tratamento } \\
\text { (métodos de avaliação) }\end{array}$} & \multicolumn{7}{|c|}{$\begin{array}{c}\text { Ensaio } \\
\text { (métodos de semeadura) }\end{array}$} \\
\cline { 2 - 7 } & 1 & 2 & 3 & 4 & 5 & 6 \\
\hline $\begin{array}{l}\text { T1- Visual } \\
\text { Urochloa ruziziensis }\end{array}$ & lanço & $\begin{array}{c}\text { Lanço com } \\
\text { incorporação }\end{array}$ & linha & lanço & $\begin{array}{c}\text { Lanço com } \\
\text { incorporação }\end{array}$ & linha \\
\hline $\begin{array}{l}\text { T2- Transecto } \\
\text { Urochloa ruziziensis }\end{array}$ & lanço & $\begin{array}{c}\text { Lanço com } \\
\text { incorporação }\end{array}$ & linha & lanço & $\begin{array}{c}\text { Lanço com } \\
\text { incorporação }\end{array}$ & linha \\
\hline $\begin{array}{l}\text { T3- Fotográfica } \\
\text { Urochloa ruziziensis }\end{array}$ & lanço & $\begin{array}{c}\text { Lanço com } \\
\text { incorporação }\end{array}$ & linha & lanço & $\begin{array}{c}\text { Lanço com } \\
\text { incorporação }\end{array}$ & linha \\
\hline $\begin{array}{l}\text { T4- Visual } \\
\text { Urochloa spp. }\end{array}$ & -- & -- & lanço & $\begin{array}{c}\text { Lanço com } \\
\text { incorporação }\end{array}$ & linha \\
\hline $\begin{array}{l}\text { T5- Transecto } \\
\text { Urochloa spp. }\end{array}$ & -- & -- & lanço & $\begin{array}{c}\text { Lanço com } \\
\text { incorporação }\end{array}$ & linha \\
\hline $\begin{array}{l}\text { T6- Fotográfica } \\
\text { Urochloa spp. }\end{array}$ & -- & -- & $\begin{array}{c}\text { Lanço com } \\
\text { incorporação }\end{array}$ & linha \\
\hline
\end{tabular}

de largura por $15 \mathrm{~m}$ de comprimento, totalizando $60 \mathrm{~m}^{2}$.

A taxa de semeadura do capim-braquiária seguiu a recomendação de pontos de valor cultural (VC), em que foram utilizados 400 pontos de $\mathrm{VC} \mathrm{ha}^{-1}$ para a semeadura a lanço e a lanço com leve incorporação e 240 pontos de $\mathrm{VC}^{-1}$ para a semeadura em linha. Para Urochloa spp. cv. Mulato II foram utilizadas sementes peletizadas, e para Urochloa ruziziensis, sementes tratadas com o inseticida fipronil.

Nas duas modalidades de semeadura a lanço, as sementes foram semeadas manualmente em área total. No método de semeadura com incorporação, realizou-se uma operação de gradagem leve com grade niveladora 'fechada', na profundidade de 0,05 m. Para a semeadura em linha, foram implantadas oito linhas em cada parcela, espaçadas de 0,45 m, com 0,05 $\mathrm{m}$ de profundidade, simulando a adoção de semeadora tratorizada.

A semeadura do capim-braquiária foi feita após a colheita da soja, em 30/03/2012, depois da dessecação da área com o herbicida glyphosate (1.440 $\mathrm{g} \mathrm{ha}^{-1}$ de e.a.).

A fração de cobertura vegetal total do solo, composta pelas braquiárias e plantas daninhas, foi avaliada aos 30, 60 e 90 dias após a semeadura (DAS). Para essa avaliação, foram adotadas três técnicas de medida: estimativa visual (Gazziero et al., 1995), estimativa pelo intercepto ou transecto de linha (Brower $\&$ Zar, 1984) e análise digital de imagem (Ferreira et al., 2001).

Na estimativa visual, foi estabelecida uma escala percentual de notas de 0 a $100 \%$, em que zero corresponde à ausência de cobertura vegetal sobre o solo e 100 à completa cobertura do solo. Na técnica do transecto de linha, utilizou-se uma corda com 100 intervalos, espaçados de $0,05 \mathrm{~m}$, somando $5 \mathrm{~m}$ de comprimento. A corda foi estendida aleatoriamente na diagonal de cada parcela, em três pontos, sendo contados os intervalos que apresentavam cobertura vegetal pela braquiária e pelas plantas daninhas. Na avaliação óptica, foram registradas fotografias, em três pontos aleatórios de cada parcela, realizada entre $9 \mathrm{~h}$ e $12 \mathrm{~h}$, a uma altura de $1,5 \mathrm{~m}$, com o uso de câmera fotográfica Sony, modelo Cyber-shot DSC-W80 de 7,2 megapixels. Para determinação da porcentagem de cobertura das fotografias, estas foram processadas utilizando o software ImageJ (Ferreira \& Rasband, 2012). Quanto ao processamento das imagens, estas foram agrupadas em três lotes $(30,60$ e 90 DAS) e, posteriormente, realizou-se a calibração de cores para o processamento dos lotes de imagens. 
Os dados das frações de cobertura vegetal do solo foram submetidos à análise de variância e, posteriormente, quando necessário, à comparação de médias pelo teste de Tukey a 5\% de significância (Banzatto \& Kronka, 2006).

\section{RESULTADOS E DISCUSSÃO}

No ensaio 1 (braquiária-ruziziense com semeadura a lanço), aos 30 DAS, não se constatou diferença entre as três técnicas de medida das frações de cobertura vegetal do solo. Aos 60 DAS, a fração de cobertura vegetal foi maior quando estimada visualmente, sem, no entanto, diferir daquela medida por imagens fotográficas. Aos 90 DAS, a fração de cobertura vegetal foi menor quando medida pela técnica fotográfica. Entretanto, vale ressaltar que os valores numéricos foram muito próximos, e o coeficiente de variação foi baixo (Tabela 2).
No método de semeadura a lanço com incorporação das sementes de braquiáriaruziziense (ensaio 2), a porcentagem de cobertura do solo por esse capim aos 30 DAS não diferiu quando submetido à análise pelas três técnicas de determinação (Tabela 2). Laflen et al. (1981) compararam as técnicas visual e por transecto com a técnica fotográfica e concluíram que as três mostraram resultados satisfatórios para a determinação da fração de cobertura do solo.

Aos 60 e 90 DAS, as análises da fração de cobertura vegetal do solo pela técnica visual e por transecto não diferiram entre si, e a medida por imagens fotográficas apresentou menor valor (Tabela 2). Para Rizzardi \& Fleck (2004), os métodos fotográficos são alternativas promissoras, porém uma das principais limitações deles é a estimativa precisa da

Tabela 2 - Valores de F, DMS e coeficientes de variação (CV\%), aplicados às médias de porcentagem de cobertura total do solo, aos 30, 60 e 90 dias após a semeadura (DAS), nos ensaios 1, 2 e 3

\begin{tabular}{|c|c|c|c|c|}
\hline & \multirow{2}{*}{ Variáveis } & \multicolumn{3}{|c|}{ Fração de cobertura vegetal (\%) } \\
\hline & & 30 DAS & 60 DAS & 90 DAS \\
\hline \multicolumn{5}{|c|}{ Ensaio 1: Urochloa ruziziensis com semeadura a lanço } \\
\hline \multirow{2}{*}{$\mathrm{F}$} & Tratamentos & $2,51^{\mathrm{ns}}$ & $6,50 *$ & $9,70 * *$ \\
\hline & Blocos & $2,99 *$ & $0,71^{\mathrm{ns}}$ & $0,74^{\mathrm{ns}}$ \\
\hline \multirow{3}{*}{$\begin{array}{l}\text { Tratamentos } \\
\text { (Técnica) }\end{array}$} & Fotografia & 28,00 a & $76,88 \mathrm{ab}$ & $97,86 \mathrm{~b}$ \\
\hline & Transecto & 33,13 a & $71,88 \mathrm{~b}$ & 99,25 a \\
\hline & Visual & 29,63 a & $80,38 \mathrm{a}$ & $100,00 \mathrm{a}$ \\
\hline DMS & & 6,11 & 6,20 & 1,28 \\
\hline CV (\%) & & 15,40 & 6,20 & 1,00 \\
\hline \multicolumn{5}{|c|}{ Ensaio 2: Urochloa ruziziensis com semeadura a lanço incorporado } \\
\hline \multirow{2}{*}{$\mathrm{F}$} & Tratamentos & $2,92^{\mathrm{ns}}$ & $40,99 * *$ & $75,35^{* *}$ \\
\hline & Blocos & $1,18^{\mathrm{ns}}$ & $0,94^{\mathrm{ns}}$ & $1,35^{\mathrm{ns}}$ \\
\hline \multirow{3}{*}{ Tratamentos } & Fotografia & 39,75 a & $73,50 \mathrm{~b}$ & $98,25 \mathrm{~b}$ \\
\hline & Transecto & 42,25 a & $87,00 \mathrm{a}$ & $99,88 \mathrm{a}$ \\
\hline & Visual & 47,13 a & $87,00 \mathrm{a}$ & $100,00 \mathrm{a}$ \\
\hline DMS & & 8,12 & 4,50 & 0,42 \\
\hline CV (\%) & & 14,40 & 4,20 & 0,30 \\
\hline \multicolumn{5}{|c|}{ Ensaio 3: Urochloa ruziziensis com semeadura em linha } \\
\hline \multirow{2}{*}{$\mathrm{F}$} & Tratamentos & $85,05^{* *}$ & $100,00 * *$ & $18,10 * *$ \\
\hline & Blocos & $2,98 *$ & $1,09^{\text {ns }}$ & $1,00^{\mathrm{ns}}$ \\
\hline \multirow{3}{*}{ Tratamentos } & Fotografia & $42,88 \mathrm{~b}$ & $72,75 \mathrm{~b}$ & $98,13 \mathrm{~b}$ \\
\hline & Transecto & $43,38 \mathrm{~b}$ & $91,63 \mathrm{a}$ & $100,00 \mathrm{a}$ \\
\hline & Visual & $63,13 \mathrm{a}$ & $88,13 \mathrm{a}$ & $100,00 \mathrm{a}$ \\
\hline DMS & & 4,63 & 3,72 & 0,94 \\
\hline $\mathrm{CV}(\%)$ & & 7,11 & 3,40 & 0,70 \\
\hline
\end{tabular}

Médias seguidas pela mesma letra, na mesma coluna, não diferem entre si pelo teste de Tukey a $\mathrm{p}<0,05$. 
cobertura foliar em baixas densidades de plantas, em virtude da não uniformidade de distribuição das plantas.

Aos 30 DAS, na semeadura em linha do capim braquiária-ruziziense (ensaio 3 ), a técnica visual superestimou o valor de cobertura do solo, em comparação com os demais métodos analisados (Tabela 2). Isso ocorreu provavelmente devido à maior uniformidade de cobertura, já que havia apenas pequenos espaços sem cobertura entre as linhas. Segundo Vitta \& Fernandez Quintanilla (1996), em baixas porcentagens de cobertura vegetal a técnica visual tende a superestimar os valores, o que corrobora os resultados obtidos. No entanto, aos 60 e 90 DAS, a técnica visual não diferiu daquela estimada por transecto, demonstrando haver semelhança entre os resultados obtidos com essas técnicas (Tabela 2). Vale ressaltar que nestas duas técnicas a determinação da fração de cobertura do solo depende do julgamento do observador. $\mathrm{Na}$ técnica visual, a principal restrição consiste na subjetividade do avaliador (Ngouajio et al., 1998, 1999). Assim, a experiência do observador pode influenciar consideravelmente os resultados (Lotz et al., 1994). Em consequência, são necessários observadores treinados para que o método possa ser confiável (Vitta \& Fernandez Quintanilla, 1996). Assim, salienta-se a necessidade de pelo menos dois observadores treinados para a execução das avaliações visuais de estimativa de cobertura vegetal sobre o solo.

No ensaio de capim braquiária-ruziziense e capim-braquiária cv. Mulato II, com semeadura a lanço (ensaio 4), as técnicas de avaliação visual e por transecto não diferiram entre si (Tabela 3), demonstrando que na avaliação visual, quando realizada por observadores treinados, têm-se resultados semelhantes aos obtidos pela técnica do transecto. Segundo Rizzardi \& Fleck (2004), a avaliação visual possui como vantagens a rapidez de execução e a possibilidade de distinguir baixas porcentagens de cobertura por diferentes espécies, sendo muito utilizada na determinação de infestação de plantas daninhas.

Quanto à fração de cobertura vegetal do solo pelas espécies de capim-braquiária, somente aos 90 DAS o capim braquiária-ruziziense apresentou fração de cobertura do solo superior à do capim braquiária cv. Mulato II, evidenciando seu maior potencial de cobertura vegetal. Já para o capim-braquiária cv. Mulato II, observou-se maior presença das plantas daninhas na cobertura do solo. O menor valor obtido na estimativa por imagem fotográfica pode estar relacionado à frutificação diferenciada das espécies presentes, uma vez que a técnica de análise digital tende a subestimar a fração de cobertura em plantas com panículas maduras, pois os órgãos das plantas se tornam mais claros (refletivos), o que dificulta a análise das imagens em lote. Para Cruz et al. (2008), os programas computacionais utilizados no processamento de imagens fotográficas são adequados para separar solo de planta, independentemente do tipo de planta usada como cobertura do solo.

$\mathrm{Na}$ semeadura a lanço com incorporação de sementes de capim-braquiária-ruziziense e capim-braquiária cv. Mulato II (ensaio 5), a fração de cobertura vegetal do solo foi superior com a braquiária-ruziziense aos 30 DAS (Tabela 3), demonstrando que a incorporação de sementes favorece a germinação e desenvolvimento desta espécie. Nesse período, as técnicas de avaliação visual e por transecto não diferiram entre si. Aos $60 \mathrm{DAS}$, houve interação significativa entre as espécies de capim-braquiária e as técnicas de análise das frações de cobertura do solo. Já aos 90 DAS, as frações de cobertura vegetal do solo, quando comparadas, não diferiram entre si. A maior fração de cobertura e uniformidade de distribuição da massa vegetal sobre o solo facilita a avaliação nos diferentes métodos. Assim, nessa situação, a área amostral tende a ser mais representativa da parcela experimental.

No método de semeadura em linha do capim-braquiária-ruziziense e capim-braquiária cv. Mulato II (ensaio 6), aos 30 DAS, não houve diferença na fração de cobertura do solo pelas três técnicas de avaliação e pelas duas espécies de capim-braquiária (Tabela 3). Aos 60 DAS, constatou-se interação significativa entre as espécies de capim-braquiária e as técnicas de avaliação. Já aos 90 DAS, a fração de cobertura do solo pelo capim-braquiária-ruziziense foi superior; nesse período, as técnicas de avaliação visual e por transecto não diferiram entre si (Tabela 3). 
Tabela 3 - Valores de F, DMS e coeficientes de variação (CV\%), aplicados às médias de porcentagem de cobertura total do solo, aos 30, 60 e 90 dias após a semeadura (DAS), nos ensaios 4, 5 e 6

\begin{tabular}{|c|c|c|c|c|}
\hline & \multirow{2}{*}{ Variáveis } & \multicolumn{3}{|c|}{ Fração de cobertura vegetal (\%) } \\
\hline & & 30 DAS & 60 DAS & 90 DAS \\
\hline \multicolumn{5}{|c|}{ Ensaio 4: Urochloa ruziziensis e Urochloa spp. cv. Mulato II com semeadura a lanço } \\
\hline \multirow{3}{*}{$\mathrm{F}$} & Braquiária (B) & $0,03^{\text {ns }}$ & $0,82^{\mathrm{ns}}$ & $6,71^{*}$ \\
\hline & Técnica (T) & $12,10^{* *}$ & $1,83^{\text {ns }}$ & $10,63 * *$ \\
\hline & $\mathrm{B} \times \mathrm{T}$ & $0,49^{\mathrm{ns}}$ & $0,08^{\mathrm{ns}}$ & $0,06^{\mathrm{ns}}$ \\
\hline \multirow{2}{*}{ Braquiária (B) } & Ruziziensis & 38,42 & 80,00 & 99,00 a \\
\hline & cv. Mulato II & 39,00 & 76,67 & $97,50 \mathrm{~b}$ \\
\hline DMS & & 7,17 & 7,85 & 1,23 \\
\hline \multirow{3}{*}{ Técnica (T) } & Fotografia & $50,38 \mathrm{a}^{\mathrm{1}^{\prime}}$ & $74,75 \mathrm{a}$ & $96,38 \mathrm{~b}$ \\
\hline & Transecto & $33,88 \mathrm{~b}$ & 77,13 a & 99,00 a \\
\hline & Visual & $31,88 \mathrm{~b}$ & $83,13 \mathrm{a}$ & 99,38 a \\
\hline DMS & & 10,71 & 11,72 & 1,84 \\
\hline CV $(\%)$ & & 21,30 & 11,50 & 1,40 \\
\hline \multicolumn{5}{|c|}{ Ensaio 5: Urochloa ruziziensis e Urochloa spp. cv. Mulato II com semeadura a lanço incorporado } \\
\hline \multirow{3}{*}{$\mathrm{F}$} & Braquiária (B) & $8,58^{*}$ & $7,70 *$ & $4,55^{*}$ \\
\hline & \begin{tabular}{|l|} 
Técnica (T) \\
\end{tabular} & $11,49^{* *}$ & $1,16^{\mathrm{ns}}$ & $0,70^{\text {ns }}$ \\
\hline & $\mathrm{B} \times \mathrm{T}$ & $0,12^{\text {ns }}$ & $5,75 *$ & $0,41^{\mathrm{ns}}$ \\
\hline \multirow{2}{*}{ Braquiária (B) } & Ruziziensis & $40,25 \mathrm{a}$ & & 98,42 \\
\hline & \begin{tabular}{|l|} 
cv. Mulato II \\
\end{tabular} & $30,50 \mathrm{~b}$ & & 93,42 \\
\hline DMS & & 7,08 & & 4,99 \\
\hline \multirow{3}{*}{ Técnica (T) } & Fotografia & $46,63 \mathrm{a}^{\mathrm{1}^{\prime}}$ & & 97,50 \\
\hline & Transecto & $29,00 \mathrm{~b}$ & & 96,13 \\
\hline & Visual & $30,50 \mathrm{~b}$ & & 94,13 \\
\hline DMS & & 10,58 & & 7,50 \\
\hline CV $(\%)$ & & 23,00 & 11,6 & 6,00 \\
\hline \multicolumn{5}{|c|}{ Ensaio 6: Urochloa ruziziensis e Urochloa spp. cv. Mulato II com semeadura em linha } \\
\hline \multirow{3}{*}{ |F } & Braquiária (B) & $2,93^{\text {ns }}$ & $19,83 * *$ & $7,89 *$ \\
\hline & Técnica (T) & $2,28^{\mathrm{ns}}$ & $16,07 * *$ & $8,20 * *$ \\
\hline & $\mathrm{B} \times \mathrm{T}$ & $0,67^{\mathrm{ns}}$ & $19,38 * *$ & $3,14^{\mathrm{ns}}$ \\
\hline \multirow{2}{*}{ Braquiária (B) } & Ruziziensis & 46,67 & & 99,33 a \\
\hline & cV. Mulato II & 39,25 & & $97,83 \mathrm{~b}$ \\
\hline DMS & & 9,22 & & 1,14 \\
\hline \multirow{3}{*}{ Técnica $(\mathrm{T})$} & Fotografia & 49,50 & & $97,37 \mathrm{~b}$ \\
\hline & Transecto & 39,50 & & $98,38 \mathrm{ab}$ \\
\hline & Visual & 39,88 & & $100,00 \mathrm{a}$ \\
\hline DMS & & 13,77 & & 1,70 \\
\hline $\mathrm{CV}(\%)$ & & 24,70 & 4,50 & 1,30 \\
\hline
\end{tabular}

Médias seguidas pela mesma letra, na mesma coluna, não diferem entre si pelo teste de Tukey a $\mathrm{p}<0,05$.

Na Tabela 4 é apresentado o desdobramento da interação significativa obtida aos 60 DAS, no ensaio 5 (braquiáriaruziziense e braquiária cv. Mulato II com semeadura a lanço e incorporação de sementes). Constatou-se que na braquiária-ruziziense não houve diferença entre as técnicas de análise da fração de cobertura vegetal do solo, o que pode estar relacionado à maior uniformidade de cobertura proporcionada por essa espécie e à ausência de frutificação dela. 
Tabela 4 - Desdobramento da interação significativa para cobertura total do solo, para os três métodos de avaliação e as duas espécies de braquiária, aos 60 dias após a semeadura, no ensaio 5

\begin{tabular}{|l|c|c|}
\hline \multirow{2}{*}{$\begin{array}{c}\text { Ensaio 5: Urochloa ruziziensis e Urochloa spp. cv. Mulato } \\
\text { II com semeadura a lanço incorporado }\end{array}$} \\
\hline \multirow{2}{*}{ Método de Avaliação } & \multicolumn{2}{|c|}{ Braquiária } \\
\cline { 2 - 3 } & Ruziziensis & cv. Mulato II \\
\hline Fotografia & 77,25 aA & 84,25 aA \\
\hline Transecto & $85,00 \mathrm{aA}$ & $63,00 \mathrm{bB}$ \\
\hline Visual & $84,25 \mathrm{aA}$ & $68,75 \mathrm{abB}$ \\
\hline DMS & \multicolumn{3}{|c|}{16,46} \\
\hline Método dentro de braquiária & \multicolumn{3}{|c|}{13,50} \\
\hline Braquiária dentro de método & \multicolumn{2}{|c|}{} \\
\hline
\end{tabular}

Médias na mesma linha, seguidas de letras maiúsculas iguais, e na mesma coluna, seguidas de letras minúsculas iguais, não diferem entre si pelo teste de Tukey a $\mathrm{p}<0,05$.

Na braquiária cv. Mulato II, observou-se maior participação da comunidade infestante de plantas daninhas na fração de cobertura do solo, as quais frutificam e senescem em diferentes períodos. Nessa espécie, a avaliação visual não diferiu da avaliação por transecto. Ainda, a fração de cobertura do solo por braquiária cv. Mulato II foi inferior pela avaliação visual e por transecto, em comparação aos resultados obtidos com a braquiáriaruziziense, demonstrando que esta espécie tem o desenvolvimento mais rápido que o da braquiária cv. Mulato II. Na técnica da imagem fotográfica, não se verificaram diferenças na cobertura vegetal entre as duas espécies de braquiária, evidenciando a dificuldade de calibração (equalização de cores, brilhos e saturação) das imagens, em virtude da não uniformidade de frutificação das espécies presentes, uma vez que as cores mais claras se separam das mais escuras, tornando-se invisiveis durante a calibração, em razão da dificuldade de detecção de tons verde-claros pelo processador digital, os quais são agrupados às cores do solo.

Na Tabela 5 é apresentado o desdobramento da interação significativa obtida no ensaio 6 (braquiária-ruziziense e braquiária cv. Mulato II com semeadura em linha), aos 60 DAS. Nota-se que as técnicas de avaliação visual e por transecto não diferiram entre si na cobertura proporcionada pela braquiáriaruziziense. No entanto, para a braquiária cv.
Mulato II as técnicas visual e fotográfica não diferiram entre si, embora esta última não tenha diferido da técnica por transecto. A fração de cobertura do solo pela braquiária cv. Mulato II foi inferior quando estimada pelas técnicas visual e transecto, demonstrando que esta espécie de braquiária possui menor potencial de ocupação da área quando comparada à braquiária-ruziziense. A não uniformidade da cobertura vegetal proporcionada pela braquiária cv. Mulato II e a maior ocorrência de plantas daninhas dificultaram a estimativa da fração de cobertura vegetal com imagens fotográficas.

Tabela 5 - Desdobramento da interação significativa para cobertura total do solo, para as três técnicas de avaliação e as duas espécies de braquiária, aos 60 dias após a semeadura, no ensaio 6

\begin{tabular}{|l|c|c|}
\hline \multicolumn{3}{|c|}{$\begin{array}{c}\text { Ensaio 6: Urochloa ruziziensis e Urochloa spp. cv. Mulato } \\
\text { II com semeadura em linha }\end{array}$} \\
\hline \multirow{2}{*}{ Método de Avaliação } & \multicolumn{2}{|c|}{ Braquiária } \\
\cline { 2 - 3 } & Ruziziensis & cv. Mulato II \\
\hline Fotografia & $74,75 \mathrm{bB}$ & $81,25 \mathrm{abA}$ \\
\hline Transecto & $90,00 \mathrm{aA}$ & $75,25 \mathrm{bB}$ \\
\hline Visual & $94,50 \mathrm{aA}$ & $82,50 \mathrm{aB}$ \\
\hline DMS & \multicolumn{3}{|c|}{6,81} \\
\hline Método dentro de braquiária & \multicolumn{3}{|c|}{5,59} \\
\hline Braquiária dentro de método & \multicolumn{2}{|c|}{} \\
\hline
\end{tabular}

Médias na mesma linha, seguidas de letras maiúsculas iguais, e na mesma coluna, seguidas de letras minúsculas iguais, não diferem entre si pelo teste de Tukey a $\mathrm{p}<0,05$

Conclui-se que, quanto maior a uniformidade da cobertura do solo pelas plantas forrageiras, mais próximos são os valores das frações de cobertura vegetal obtidas pelas três técnicas de estimativa. A estimativa da fração de cobertura do solo pelas técnicas de avaliação visual e por transecto apresentou valores significativamente semelhantes. Já a eficiência do método de avaliação por imagem fotográfica depende da calibração individual de cada imagem, para que o aplicativo reconheça as cores de tons verde-claros como cobertura vegetal.

\section{LITERATURA CITADA}

BANZATTO, D. A.; KRONKA, S. N. Experimentação agrícola. 4.ed. Jaboticabal: Funep, 2006. 237 p. 
BERTI, A.; SATIN, M. Effect of weed position on yield loss in soybean and a comparison between relative weed cover and other regression models. Weed Res., v. 36, n. 3, p. 249-258, 1996.

BROWER, J. E.; ZAR, J. H. Field and laboratory methods for general ecology. 2.ed. Dubuque: Wm. C. Brown Company Publishers, 1984. 226 p.

CERETTA, C. A. et al. Manejo da adubação nitrogenada na sucessão aveia preta/milho, no sistema plantio direto.

R. Bras. Ci. Solo, v. 26, n. 1, p. 163-171, 2002.

CRUZ, E. S. et al. Comparação de classificadores de imagens digitais na determinação da cobertura do solo. Eng. Agríc., v. 28, n. 2, p. 237-244, 2008.

\section{EMPRESA BRASILEIRA DE PESQUISA}

AGROPECUÁRIA - EMBRAPA. Centro Nacional de Pesquisa de Solos. Sistema brasileiro de classificação de solos. 2.ed. Rio de Janeiro: 2006. 306 p.

FERREIRA, T.; RASBAND, W.S. ImageJ User Guide - IJ 1.46. 2012. 288 p. Disponível em: <http://rsbweb.nih.gov/ij/ docs/user-guide.pdf>.

FERREIRA, M. E. et al. Uso de Imagens digitais na avaliação da cobertura do solo. Planaltina: Embrapa Cerrados, 2001. 50 p. (Boletim de Pesquisa e Desenvolvimento, 21).

GAZZIERO, D. L. P.; VELINI, E. D.; OSIPE, R. Procedimentos para instalação, avaliação e análise de experimentos com herbicidas. Londrina: Sociedade Brasileira da Ciência das Plantas Daninhas, 1995. 42 p.

GODOY, L. J. G. et al. Análise de imagem digital para estimativa da área foliar em plantas de laranja "Pêra". R. Bras. Frutic., v. 29, n. 3, p. 420-424, 2007.

IKEDA, F. S. et al. Banco de sementes no solo em sistemas de cultivo lavoura-pastagem. Pesq. Agropec. Bras., v. 42, n. 11, p. 1545-1551, 2007.

KARCHER, D. E.; RICHARDSON, M. D. Quantifying turfgrass color using digital image analysis. Crop Sci., v. 43, n. 3, p. 943-951, 2003.

KROPFF, M. J.; SPITTERS, J. T. A simple model of crop loss by weed competition from early observations on relative leaf area of the weeds. Weed Res., v. 31, n. 2, p. 97-105, 1991.
LAFLEN, J. M.; AMAMIYA, M.; HINTZ, E. A. Measuring crop residue cover. J. Soil Water Conserv., v. 36, n. 6, p. 341-343, 1981.

LOTZ, L. A. P. et al. Techniques to estimate relative leaf area and cover of weeds in crops for yield loss prediction.

Weed Res., v. 34, n. 3, p. 167-175, 1994.

MACHADO, L. A. Z.; ASSIS, P. G. G. Produção de palha e forragem por espécies anuais e perenes em sucessão à soja.

Pesq. Agropec. Bras., v. 45, n. 4, p. 415-422, 2010.

NGOUAJIO, M. et al. Validation of an operator-assisted module to measure weed and crop leaf cover by digital image analysis. Weed Technol., v. 12, n. 3, p. 446-453, 1998.

NGOUAJIO, M.; LEIMIEUX, C.; LEROUX, G. D. Prediction of corn (Zea mays) yield loss from early observations of the relative leaf area and the relative leaf cover of weeds. Weed Sci., v. 47, n. 3, p. 297-304, 1999.

NOCE, M. A. et al. Influência da palhada de gramíneas forrageiras sobre o desenvolvimento da planta de milho e das plantas daninhas. R. Bras. Milho Sorgo, v. 7, n. 3, p. 265-278, 2008.

NUNES, U. R. et al. Produção de palhada de plantas de cobertura e rendimento do feijão em plantio direto. Pesq. Agropec. Bras., v. 41, n. 6, p. 943-948, 2006.

RIZZARDI, M. A.; FLECK, N. G. Métodos de quantificação da cobertura foliar da infestação de plantas daninhas e da cultura da soja. Ci. Rural, v. 34, n. 1, p. 13-18, 2004.

SODRÉ FILHO, J. et al. Culturas de sucessão ao milho na dinâmica populacional de plantas daninhas. Sci. Agr., v. 9, n. 1, p. 7-14, 2008.

TIMOSSI, P. C.; DURIGAN, J. C.; LEITE, G. J. Formação de palhada por braquiárias para adoção do sistema plantio direto. Bragantia, v. 66, n. 4, p. 617-622, 2007.

VARELLA, C. A. A. et al. Determinação da cobertura do solo por análise de imagens e redes neurais. R. Bras. Eng. Agríc. Amb., v. 6, n. 2, p. 225-229, 2002.

VITTA, J. I.; FERNANDEZ QUINTANILLA, C. Canopy measurements as predictors of weed-crop competition. Weed Sci., v. 44, n. 3, p. 511-516, 1996. 